\title{
Primary giant lymphoma of the right thigh: A case report and brief review of the literature
}

\author{
YU-HUAN GAO ${ }^{1}$, QIAN XU ${ }^{2}$, GUANGCHUAN WEI ${ }^{3}$, HAI-SHENG LIU $^{1}$, XIAOLIN WU $^{1}$, \\ LI-HONG LIU $^{1}$, LI-LI WU ${ }^{1}$, GUI-MIN ZHAO ${ }^{1}$ and LAN-PING DIAO ${ }^{1}$ \\ Departments of ${ }^{1}$ Hematology, ${ }^{2}$ Radiology and ${ }^{3}$ Ophthalmology, Hebei Medical University, \\ Fourth Hospital, Shijiazhuang, Hebei 050011, P.R. China
}

Received March 17, 2012; Accepted June 27, 2012

DOI: $10.3892 / \mathrm{ol} .2012 .848$

\begin{abstract}
Primary soft tissue non-Hodgkin lymphoma (NHL) of the extremities is very rare. The clinical features of NHL mimic those of other soft tissue tumors, particularly sarcoma; however, they should be differentiated, as the treatment and prognosis are completely different. In this study, the case of a 68-year-old female with a giant mass, movement disorder, numbness and painful sensations in the right thigh is presented. Magnetic resonance (MR) imaging revealed a huge circle-shaped mass. Fine needle aspiration cytology (FNAC) of the tumor demonstrated neoplastic small, round cells. The tentative diagnosis was of a mesenchymal sarcoma. The right thigh was amputated. On histological examination of the amputated extremity, the diagnosis was found to be large B cell lymphoma. Primary soft tissue NHL of the extremities is a systemic malignant disease and is sensitive to chemotherapy and radiotherapy. The histological diagnosis should be identified as far as possible before the tumor is widely excised.
\end{abstract}

\section{Introduction}

Non-Hodgkin lymphoma (NHL) arising from the soft tissue of the extremities is rare (1), and its clinical manifestation and defects observed on magnetic resonance imaging and computed tomography are characteristic features. In this study, we describe a 68 -year-old female with primary extranodal NHL of the right thigh, which was amputated. The diagnosis was formally established by pathology. The study shows that tumor tissue immunohistochemical features are the most important factors in the histological diagnosis of NHL.

Correspondence to: Dr Lan-Ping Diao, Department of Hematology, Hebei Medical University, Fourth Hospital, 12 Jiankang Road, Shijiazhuang, Hebei 050011, P.R. China

E-mail: diaolanping@163.com

Key words: non-Hodgkin lymphoma, soft tissue, amputation, extremity

\section{Case report}

A 68-year-old female presented to the Department of Orthopaedics with a 2-month history of a mass in the posterior part of the right thigh and a 1-month history of movement disorder of the right lower leg, with numbness and a painful sensation in the area. The patient was apparently well prior to the illness and her past medical history was uneventful. Physical examination revealed a well-nourished older woman with no abnormal findings on systemic examination. No palpable cervical, axillary or inguinal lymphadenopathy was observed. The patient was found to have a huge undefined, thick, swollen and fleshy mass of approximately 22x15x10 cm occupying the majority of the posterior part of the right thigh, with a similar mass of approximately $10 \times 8 \times 6 \mathrm{~cm}$ at the proximal posterior area of the right leg, and movement disorder of the right lower leg. Fine needle aspiration cytology (FNAC) of the tumor demonstrated neoplastic small, round cells, which were considered to indicate a mesenchymal tissue tumor.

Magnetic resonance (MR) imaging revealed an approximate circle-shaped mass measuring $21 \times 12 \times 9.5 \mathrm{~cm}$ at the posterior aspect of the right thigh (Fig. 1). The lesion showed lower signal intensity on T1-weighted images and uneven higher signal intensity on T2-weighted images. Compression and aversion of the muscles and blood vessels in the peripheral region of the lesion were also noted. Muscular fibers in some planes of the images demonstrated separation and looseness. The sclerotin of adjacent bone appeared normal in all planes of the images (Fig. 2). Tentative diagnoses included mesenchymal sarcomas, such as malignant fibrous histiocytoma and liposarcoma.

Extended resection of the soft connective tissue tumor of the right thigh was performed. Due to the huge size of the mass and involvement of the femoral artery, femoral vein and sciatic nerve, it was difficult to separate and excise the tumor, therefore the patient was treated with right hip disarticulation with the permission of the family. Biopsy of the excised mass was performed and histopathological examination revealed a diagnosis of NHL of the soft tissue. Immunohistochemical study revealed that the neoplastic cells were of B cell origin: positive for CD20; negative for CD3, Myo, Des, PTAH and $\mathrm{S}-100$. Expression of Ki-67 was observed in $50 \%$ of the cells. Therefore, a diagnosis of diffuse large B cell lymphoma was made. 


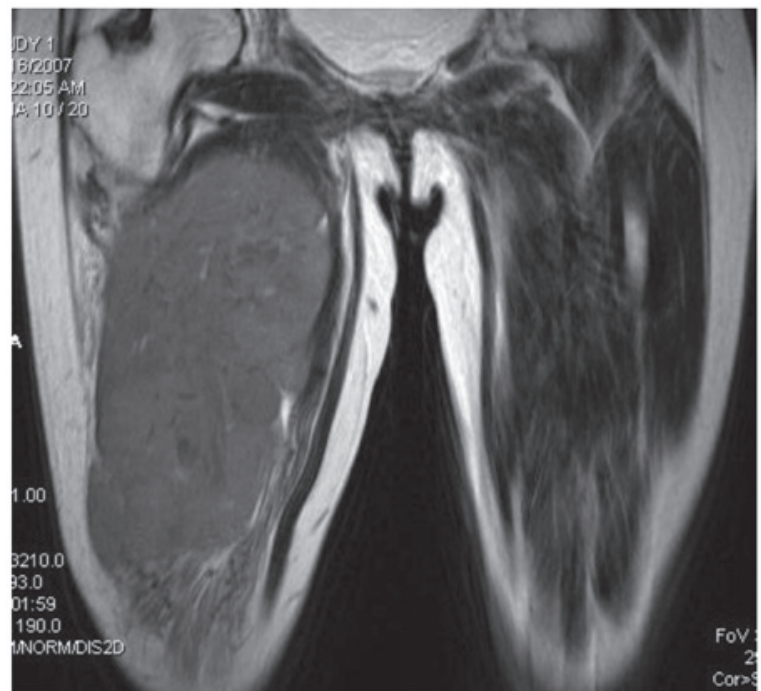

Figure 1. Magnetic resonance imaging of the right thigh. T1WI-MRI coronal image showing an approximately circle-shaped mass measuring $21 \times 12 \times 9.5 \mathrm{~cm}$ in size at the posterior aspect of the right thigh. The lesion showed lower signal intensity.

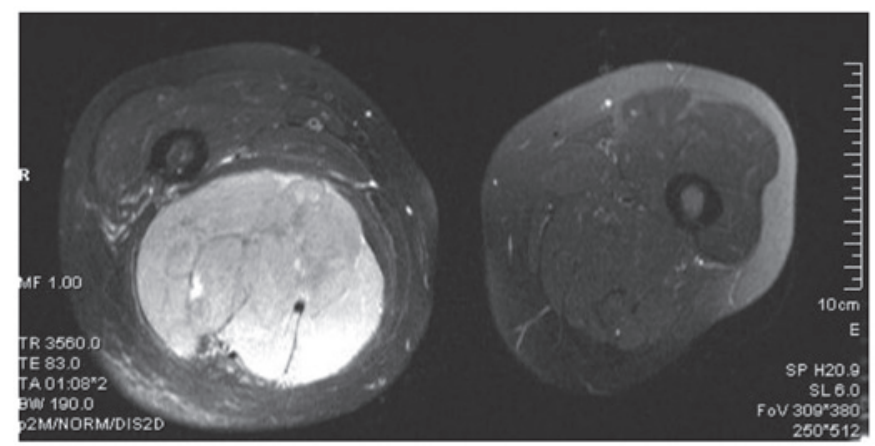

Figure 2. Magnetic resonance imaging of the right thigh. The T2WI-MRI axial image shows uneven high signal intensity of the neoplasm. The border is clearly defined. The muscles and blood vessels in the peripheral region of the lesion were compressed. The sclerotin of the adjacent bone appeared normal in all planes of the images.

Following surgery, the patient was referred to the Department of Hematology for further evaluation. Following a detailed inquiry, a medical history of night-sweats and loss of weight was found. Hematological and biochemical work-up revealed the following results: $106 \mathrm{~g} / 1$ of hemoglobin $(\mathrm{Hb})$, $209 \times 10^{9} / 1$ of platelets, a white blood cell count of $8.5 \times 10^{9} / 1$, $24.8 \mathrm{~g} / 1$ of albumin, normal levels of lactate dehydrogenase $(\mathrm{LDH})$ and $\beta 2$ microglobulin, and normal renal and liver function. Bone marrow smears displayed reactive plasmacytosis. The chest X-ray and abdominal ultrasonogram were normal. The patient refused chemotherapy. Approximately 23 days later, a rapidly growing mass in the right gluteal region was observed, and clinical examination revealed a diffuse lump in the left gluteal area. The subsequent non-contrast computed tomography (CT) scan of the right hip region revealed a diffuse, hypodense soft tissue mass with a diameter of $10 \mathrm{~cm}$ in the right gluteal area. Involvement of the right pelvis was found (Fig. 3). The disease was progressive and 50 days later, contrast-enhanced CT of the right gluteal area showed that

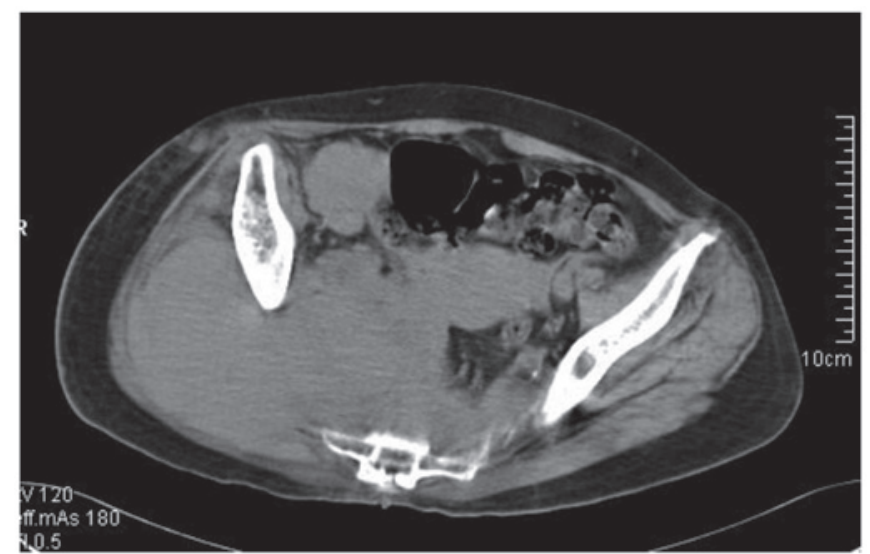

Figure 3. Computerized tomography scan showed a soft tissue mass with the diameter of $10 \mathrm{~cm}$ in the right gluteus area with irregular contours and right pelvic involvement.

there was a huge soft tissue mass with irregular contours in the right hip area, which extended to the cavity of the pelvis. On some planes of the image, there was no clear boundary between the mass and uterus. Sclerotin of the right ala of the ilium, pubis, femoral head and acetabulum was destroyed. The patient was subsequently staged as IVB (Ann Arbor staging), and received a cycle of CHOP (cyclophosphamide, adriamycin, vincristine and prednisolone) chemotherapy. A transient clinical improvement was achieved and the patient's symptoms improved. However, she could not be given further therapy, and her condition deteriorated rapidly. The patient succumbed to the disease 6 months later.

\section{Discussion}

Malignant lymphoma may present in any region of the body. The condition is referred to as primary extranodal NHL when the extranodal site is the only site involved or when the bulk of the disease is confined to the extranodal site (2). The most common extranodal sites include the gastrointestinal tract, Waldeyer's ring, head and neck, testes, ovary, central nervous system, thyroid, breast, bone and skin, in order of decreasing frequency (3-13). Primary NHL localized in the soft tissue of the extremities is uncommon. Certain reports suggest that true primary NHL in the soft tissue of the extremities represents approximately $0.11 \%$ of all malignant lymphomas (1). Meanwhile, diseases such as lymphoma or pseudolymphoma of the skin, histocytic variants of malignant fibrohistiocytoma or manifestations of systemic lymphoma should be ruled out at the time of diagnosis. The symptoms are nonspecific and may mimic other entities, such as rhabdomyosarcoma, Ewing's sarcoma, fibrosarcoma, liposarcoma, synoviosarcoma and metastatic carcinoma. As a consequence of its low incidence, a standard treatment for primary soft tissue non-Hodgkin lymphoma has not been clearly defined. Considering that the therapy for malignant lymphoma is very different from that for other soft tissue malignancies, accurate diagnosis should be established prior to definitive treatment.

Several studies have found MR imaging to be superior in the evaluation of soft tissue tumors compared with CT (14-16). There are a few reports describing the MR imaging findings 
of lymphoma in the soft tissue of the extremities $(1,17)$ : a large soft tissue mass with equal to slightly low signal intensity on T1-weighted images and markedly high signal intensity on conventional T2-weighted images, without osseous involvement, but with infiltration of skeletal muscle and surrounding soft tissues was observed. Therefore, Lee et al (17) recommend that, at MR imaging, if a large soft-tissue mass with normal adjacent bone marrow or a mass more extensive than the adjacent bone marrow abnormalities that affects a long segment of an extremity with diffuse muscle involvement is observed, and there is the presence of subcutaneous stranding or extension, the differential diagnosis should include and favor primary soft tissue lymphoma in the absence of a history of trauma or infection. CT is commonly the imaging method of choice for the detection and staging of lymphoma (18). CT enables accurate measurement of both the size and extent of the tumor, and provides information to determine appropriate therapy and response to treatment.

The diagnosis of lymphoma should be based on the histological examination. However, there are cases in which biopsy specimens are too difficult to acquire; therefore, fine-needle aspiration cytology (FNAC) becomes an acceptable alternative diagnostic procedure with excellent accuracy (19). The usefulness of FNAC in the differential diagnosis of soft tissue tumors has been discussed in detail in other studies (20-23). Since the architectural features of tumors are an important element in histological diagnosis, the main limitation of FNAC is that it does not always yield information about tumor tissue architecture and occasionally the cytological smears are not adequate for ancillary studies (24), so histology is preferable. Therefore, in the guidelines published by the National Comprehensive Cancer Network (NCCN), FNAC is not recommended for the diagnosis of NHL. On account of FNAC being a primary diagnostic tool for all soft tissue tumors, a differential diagnosis of lymphoma should always be kept in mind for other small, round-cell malignant tumors. Such cases require biopsy confirmation and immunophenotyping for further subtyping.

The histological subtype, location and the approach to therapy appear to have some correlation with the clinical outcome of soft tissue lymphoma of the extremities (1). Our patient presented to the Department of Orthopaedics with a bulky tumor at the thigh, with a size larger than $10 \mathrm{~cm}$. Preoperatively, MR imaging revealed a huge mass with a lower signal intensity on T1-weighted images and a higher signal intensity on T2-weighted images. Adjacent muscles and blood vessels were involved without adjacent osseous destruction. The primary diagnosis was malignant mesenchymoma according to FNAC, and the patient's right thigh was then amputated. Histopathological examination showed diffuse large B cell NHL, a high-grade malignancy. Postoperative CT revealed a large soft tissue mass in the right gluteal area with significant involvement of the cavity of the pelvis and uterus. The sclerotin of the adjacent bone was infiltrated. The patient succumbed 6 months after the initial surgery and diagnosis. Based on these observations, our patient had a very aggressive lymphoma with high probability for infiltration.

In conclusion, surgical excision is the main treatment for most primary soft tissue sarcomas. Nevertheless, primary extremity lymphomas are rare tumors with potentially high malignancy and metastatic capacity, exhibiting clinical and histological difficulty for a correct diagnosis. The presence of an intense soft tissue mass on MR imaging, particularly in a middle- or older-aged patient, is highly suggestive of lymphoma. Considering the sensitivity to chemotherapy and radiotherapy, amputation of the extremity is not optimal for lymphomas. FNAC is seldom adequate to establish diagnosis, and biopsy of the mass and histopathological examination are essential to distinguish lymphoma from other malignant round-cell tumors. Early recognition and correct diagnosis will allow the proper treatment protocol to be initiated.

\section{Acknowledgements}

This study was supported in part by the Institution of Higher Learning Strong and Special Subjects Item Foundation, Hebei Province, China.

\section{References}

1. Travis WD, Banks PM and Reiman HM: Primary extranodal soft tissue lymphoma of the extremities. Am J Surg Pathol 11: 359-366, 1987.

2. Komaki R, Cox J, Hansen R, Gunn W and Greenberg M: Malignant lymphoma of the uterus and cervix. Cancer 54: 1699-1704, 1984.

3. Hariprasad R, Kumar L, Bhatla DM, Kukreja M and Papaiah S: Primary uterine lymphoma: Report of 2 cases and review of literature. Am J Obstet Gynecol 195: 308-313, 2006.

4. Kolve ME, Fischbach W and Wilhelm M: Primary gastric nonHodgkin's lymphoma: requirements for diagnosis and staging. Recent Results Cancer Res 156: 63-68, 2000.

5. Laskar S, Mohindra P, Gupta S, Shet T and Muckaden MA: Non-Hodgkin lymphoma of the Waldeyer's ring: clinicopathologic and therapeutic issues. Leuk Lymphoma 49: 2263-2271, 2008.

6. King AD, Lei KI and Ahuja AT: MRI of neck nodes in nonHodgkin's lymphoma of the head and neck. Br J Radiol 77: 111-115, 2004.

7. Sasai K, Yamabe H, Tsutsui K, Dodo Y, Ishigaki T, Shibamoto Y and Hiraoka M: Primary testicular non-Hodgkin's lymphoma: a clinical study and review of the literature. Am J Clin Oncol 20: 59-62, 1997.

8. Ray S, Mallick MG, Pal PB, Choudhury MK, Bandopadhyay A and Guha D: Extranodal non-Hodgkin's lymphoma presenting as an ovarian mass. Indian J Pathol Microbiol 51: 528-530, 2008.

9. Camilleri-Broët S, Martin A, Moreau A, Angonin R, Hénin D, Gontier MF, Rousselet MC, Caulet-Maugendre $S$, Cuillière $P$, Lefrancq T, et al: Primary central nervous system lymphomas in 72 immunocompetent patients: pathologic findings and clinical correlations. Am J Clin Pathol 110: 607-612, 1998.

10. Colović M, Matić S, Kryeziu E, Tomin D, Colović N and Atkinson HD: Outcomes of primary thyroid non-Hodgkin's lymphoma: a series of nine consecutive cases. Med Oncol 24: 203-208, 2007.

11. Hinoshita E, Tashiro H, Takahashi I I, Onohara T, Nishizaki T, Matsusaka T, Wakasugi K, Ishikawa T, Kume K, Yamamoto I and Hirota Y: Primary non-Hodgkin's lymphoma of the breast: a report of two cases. Breast Cancer 5: 309-312, 1998.

12. Pant V, Jambhekar NA, Madur B, Shet TM, Agarwal M, Puri A, Gujral S, Banavali M and Arora B: Anaplastic large cell lymphoma (ALCL) presenting as primary bone and soft tissue sarcoma - a study of 12 cases. Indian J Pathol Microbiol 50: 303-307, 2007.

13. Theander E, Henriksson G, Ljungberg O, Mandl T, Manthorpe R and Jacobsson LT: Lymphoma and other malignancies in primary Sjögren's syndrome: a cohort study on cancer incidence and lymphoma predictors. Ann Rheum Dis 65: 796-803, 2006.

14. Lai YC, Chiou HJ, Wu HT, Chou YH, Wang HK and Chen PC: Ultrasonographic and MR findings of alveolar soft part sarcoma. J Chin Med Assoc 72: 336-339, 2009.

15. Kransdorf MJ, Jelinek JS and Moser RP Jr: Imaging of soft tissue tumors. Radiol Clin North Am 31: 359-372, 1993. 
16. Verstraete KL and Lang P: Bone and soft tissue tumors: the role of contrast agents for MR imaging. Eur J Radiol 34: 229-246, 2000.

17. Lee VS, Martinez S and Coleman RE: Primary muscle lymphoma: clinical and imaging findings. Radiology 203: 237-244, 1997.

18. Fishman EK, Kuhlman JE and Jones RJ: CT of lymphoma: spectrum of disease. Radiographics 11: 647-669, 1991.

19. Daskalopoulou D, Rapidis AD, Maounis N and Markidou S: Fine-needle aspiration cytology in tumors and tumor-like conditions of the oral and maxillofacial region: diagnostic reliability and limitations. Cancer 81: 238-252, 1997.

20. Dey P, Mallik MK, Gupta SK and Vasishta RK: Role of fine needle aspiration cytology in the diagnosis of soft tissue tumours and tumour-like lesions. Cytopathology 15: 32-37, 2004.
21. Amin MS, Luqman M, Jamal S, Mamoon N and Anwar M: Fine needle aspiration biopsy of soft tissue tumours. J Coll Physicians Surg Pak 13: 625-628, 2003.

22. Bennert KW and Abdul-Karim FW: Fine needle aspiration cytology vs. needle core biopsy of soft tissue tumors. A comparison. Acta Cytol 38: 381-384, 1994.

23. Mathur S, Dawar R and Verma K: Diagnosis and grading of nonHodgkin's lymphomas on fine needle aspiration cytology. Indian J Pathol Microbiol 50: 46-50, 2007.

24. Domanski HA, Akerman M, Carlén B, Engellau J, Gustafson P, Jonsson K, Mertens F and Rydholm A: Core-needle biopsy performed by the cytopathologist, a technique to complement fine-needle aspiration of soft tissue and bone lesions. Cancer (Cancer Cytopathol) 105: 229-239, 2005. 